einstein

Official Publication of the Instituto Israelita de Ensino e Pesquisa Albert Einstein

ISSN: 1679-4508 | e-ISSN: 2317-6385

\title{
Quantitative analysis in COVID-19: report of an initial experience
}

\author{
Análise quantitativa na COVID-19: relato de uma \\ experiência inicial
}

Fábio Augusto Ribeiro Dalprá1, Eduardo Kaiser Ururahy Nunes Fonseca', Gilberto Szarf ${ }^{1}$, Rodrigo Caruso Chate ${ }^{1}$

${ }^{1}$ Hospital Israelita Albert Einstein, São Paulo, SP, Brazil.

DOI: 10.31744/einstein_journal/2020AI5842
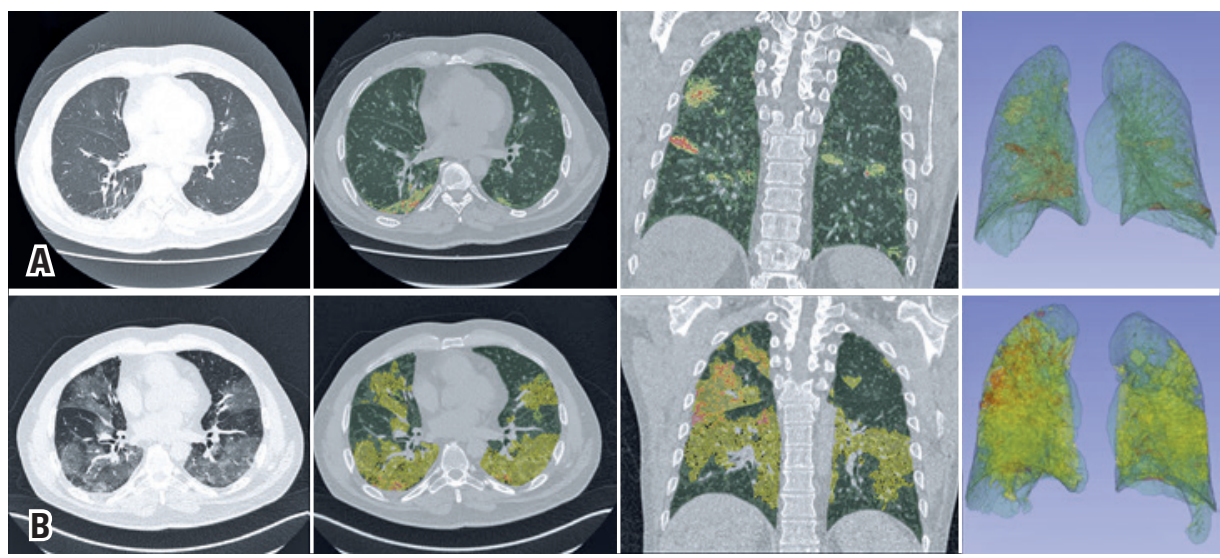

Figure 1. Chest computed tomography and superimposed 3DSlicer software quantification images. The upper series $(A)$ show the findings when the patient returned to the emergency room, and the lower series $(B)$ show the findings at the time of his clinical worsening. Axial sections of the chest tomography showing multifocal pulmonary ground-glass opacities predominantly peripheral and basal, more extensive in the last study, and quantitative images generated by the 3DSlicer software superimposed over the tomographic images. The areas marked in yellow show ground-glass opacities, those marked in green are areas of normal parenchyma, and those marked in orange are areas of consolidation. The extensive progression of the findings illustrates the numerical data provided

How to cite this article:

Dalprá FA, Fonseca EK, Szarf G, Chate RC Quantitative analysis in COVID-19: report of an initial experience. einstein (São Paulo). 2020;18:eAl5842. http://dx.doi.org/10.31744/ einstein journal/2020Al5842

\section{Corresponding author:}

Eduardo Kaiser Ururahy Nunes Fonseca Avenida Albert Einstein, 627/701 - Morumbi Zip code: 05652-900 - São Paulo, SP, Brazil Phone: (55 11) 2151-1233

E-mail: eduardo.ururahy@einstein.br

\section{Received on:}

May 10, 2020

\section{Accepted on:}

July 27, 2020

\section{Copyright 2020}

\section{(cc) BY}

This content is licensed

under a Creative Commons

Attribution 4.0 International License.
A 63-year-old man came to the emergency room complaining of unverified fever and myalgia. Oropharyngeal material was collected for reverse transcription testing followed by polymerase chain reaction (RT-PCR) for coronavirus disease 2019 (COVID-19), and a chest radiography was performed (normal), and the patient was discharged to home isolation, due to his mild symptoms, until the test result.

After 3 days, the patient evolved with dyspnea, a drop in oxygen saturation $(95 \%)$, and measured fever $\left(38.6^{\circ} \mathrm{C}\right)$, and a chest computed tomography was performed (Figure 1) and he was admitted to hospital. The RT-PCR test for COVID-19 was positive.

Three days later, his respiratory pattern worsened, with a decrease in oxygen saturation to $90 \%$, and he was referred to a stepdown unit and a new tomography was performed (Figure 1).

An 80-row CT scanner (Aquillion Prime, Canon Medical Systems, Tochigi, Japan) was used, with the patient in supine position, during maximum inspiration, and without injection of contrast medium. The following parameters were 
used: reconstructions with slice-thickness of $1 \mathrm{~mm}$, a tube voltage of $80 \mathrm{kVp}$ to $120 \mathrm{kVp}$, and adjustable current, varying between $10 \mathrm{~mA}$ and $440 \mathrm{~mA}$. The images of these two exams were then processed, using the 3DSlicer software to segment the normal parenchyma, groundglass opacities and consolidation areas in both lungs in the two exams performed for the patient (Figure 1).

From this, a quantitative analysis was conducted, showing in the first study a total lung volume of $4,289.62 \mathrm{~cm}^{3}$, with the right lung measuring $2,214.91 \mathrm{~cm}^{3}$ and the left lung measuring $2,074.71 \mathrm{~cm}^{3}$. The preserved parenchyma area measured $2,110.48 \mathrm{~cm}^{3}(95.29 \%)$ in the right lung, and $2,056.79 \mathrm{~cm}^{3}(99.14 \%)$ in the left lung. The right lung presented with $81.01 \mathrm{~cm}^{3}(3.66 \%)$ of ground-glass opacities and $23.42 \mathrm{~cm}^{3}(1.06 \%)$ of consolidations; the left lung presented with $14.98 \mathrm{~cm}^{3}$ $(0.72 \%)$ of ground-glass opacities, and $2.95 \mathrm{~cm}^{3}(0.14 \%)$ of consolidations. In total, the patient had $2.85 \%$ of parenchyma affected by ground-glass opacities or consolidations in the first study.

In the second study, the total lung volume calculated was $3,569.85 \mathrm{~cm}^{3}$, with $1,814.95 \mathrm{~cm}^{3}$ in the right lung and $1,754.90 \mathrm{~cm}^{3}$ in the left lung. The preserved parenchyma area measured $915.17 \mathrm{~cm}^{3}(50.42 \%)$ in the right lung, and $1,301.17 \mathrm{~cm}^{3}(74.15 \%)$ in the left lung. The ground-glass opacity areas totaled $857.49 \mathrm{~cm}^{3}(47.25 \%)$ in the right lung, and $447.63 \mathrm{~cm}^{3}(25.51 \%)$ in the left lung, and the consolidation areas totaled $42.29 \mathrm{~cm}^{3}(2.33 \%)$ in the right lung, and $6.09 \mathrm{~cm}^{3}(0.35 \%)$ in the left lung.

In three days of progression, the patient showed an increase of $1,259.93 \%$ in ground-glass opacity volume, with $958.47 \%$ in the right lung, and $2,888.06 \%$ in the left lung, and an $83.44 \%$ increase in the consolidation volume, with $80.57 \%$ in the right lung, and $106.66 \%$ in the left lung. These numbers resulted in a $46.81 \%$ reduction in the preserved parenchyma volume, with a reduction of $56.64 \%$ in the right lung, and $36.74 \%$ in the left lung.

\section{DISCUSSION}

Several cases of pneumonia of unknown origin that occurred in Wuhan, China, in late 2019, led to the discovery of a new type of coronavirus (2019-nCoV), called novel coronavirus-infected pneumonia (COVID-19).(1-4) The virus quickly spread and started to affect individuals outside the initial contagion area, in other countries and, finally, on all continents, and was declared a pandemic by the World Health Organization (WHO) ${ }^{(1-4)}$

The 3DSlicer software is a free tool available online for download, whose use in quantitative imaging is well-established, having even been used in the evaluation of pulmonary nodules in chest imaging. ${ }^{(5-7)}$

Much has been studied since the beginning of the pandemic about the role of imaging tests in the prognosis and progressive control of COVID-19 patients, but a forceful answer has yet to be found. Our service, for instance, has been using the assessment of the tomographic progression of the disease as an auxiliary criterion in the clinical decision of hospitalization. The present case demonstrates the use of the 3DSlicer tool for the quantification of pulmonary tomographic changes, applied in the clinical monitoring of the patient, enabling an objective estimation of the involvement percentage and the progression rate of the disease. We believe that this tool can be an important resource for borderline cases or those that raise doubts about the significance of the progression. In addition, its association with artificial intelligence strategies can optimize the quantification process, rendering it possible the use of this quantification in a greater number of cases.

\section{AUTHORS' INFORMATION}

Dalprá FA: http://orcid.org/0000-0003-2448-5826

Fonseca EK: http://orcid.org/0000-0002-0233-0041

Szarf G: http://orcid.org/0000-0002-1941-7899

Chate RC: http://orcid.org/0000-0002-4193-7647

\section{REFERENCES}

1. World Health Organization (WHO). Emergencies preparedness, response. Novel Coronavirus - Republic of Korea (ex-Chin) [Internet]. Geneva: WHO; 2020 [cited 2020 Mar 30]. Available from: https://www.who.int/csr/don/21 january-2020-novel-coronavirus-republic-of-korea-ex-china/en/

2. World Health Organization (WHO). WHO Director-General's opening remarks at the media briefing on COVID-19 -11 March 2020 [Internet]. Geneva: WHO; 2020 [cited 2020 May 12]. Available from: https://www.who.int/dg/ speeches/detail/who-director-general-s-opening-remarks-at-the-mediabriefing-on-covid-19---7-september-2020

3. Wu Z, McGoogan JM. Characteristics of and important lessons from the coronavirus disease 2019 (COVID-19) outbreak in China: summary of a report of 72314 cases from the Chinese Center for Disease Control and Prevention. JAMA. 2020;323(13):1239-42.

4. National Health Commission of the People's Republic of China. New coronavirus cases rise to 571 in Chinese mainland [Internet]. Beijing (CHN): National Health Commission of the People's Republic of China; 2020 [cited 2020 Mar 16]. Available from: http://en.nhc.gov.cn/2020-01/23/c 76004.htm

5. 3DSlicer Main Page. Welcome to the 3D Slicer Wiki pages [Internet] 3DSlicer; 2019 [cited 2020 Mar 30]. Available from: https://www.slicer.org/ wiki/Main Page

6. Kikinis R, Pieper SD, Vosburgh KG. 3D Slicer: a platform for subject-specific image analysis, visualization, and clinical support. in: Jolesz FA, editor Intraoperative Imaging and Image-Guided Therapy. Springer: New York; 2014. p. 277-89.

7. Yip SS, Parmar C, Blezek D, Estepar RS, Pieper S, Kim J, et al. Application of the 3D slicer chest imaging platform segmentation algorithm for large lung nodule delineation. PLoS One. 2017;12(6):e0178944. 